\title{
Comparison of Effects of Acidic Electrolyzed Water and NaOCI on Tilletia indica Teliospore Germination
}

\author{
M. R. Bonde and S. E. Nester, USDA-ARS, Foreign Disease-Weed Science Research Unit, Fort Detrick, MD \\ 21702-5023; A. Khayat, Hunt Wesson, Inc., Fullerton, CA 92833; J. L. Smilanick, USDA-ARS, Horticultural \\ Crops Research Laboratory, Fresno, CA 93727; and R. D. Frederick and N. W. Schaad, USDA-ARS, Foreign Dis- \\ ease-Weed Science Research Unit, Fort Detrick, MD 21702-5023
}

\begin{abstract}
Bonde, M. R., Nester, S. E., Khayat, A., Smilanick, J. L., Frederick, R. D., and Schaad, N. W. 1999. Comparison of effects of acidic electrolyzed water and $\mathrm{NaOCl}$ on Tilletia indica teliospore germination. Plant Dis. 83:627-632.

Definitive identification of free teliospores of Tilletia indica, causal agent of Karnal bunt of wheat, requires polymerase chain reaction (PCR)-based diagnostic tests. Since direct PCR amplification from teliospores has not been reliable, teliospores first must be germinated in order to obtain adequate DNA. We have routinely surface-sterilized teliospores for 2 min with $0.4 \%$ ( $\mathrm{vol} / \mathrm{vol})$ sodium hypochlorite $(\mathrm{NaOCl})$ to stimulate germination and produce axenic cultures. However, we observed that some spores were killed even with a 2-min $\mathrm{NaOCl}$ treatment, the shortest feasible duration. Decreasing the $\mathrm{NaOCl}$ concentration in our study from $0.4 \%$ to 0.3 and $0.2 \%$, respectively, increased teliospore germination, but treatment times longer than $2 \mathrm{~min}$ still progressively reduced the germination percentages. In testing alternative methods, we found "acidic electrolyzed water" (AEW), generated by electrolysis of a weak solution of sodium chloride, also surface-sterilized and increased the rate of $T$. indica teliospore germination. In a representative experiment comparing the two methods, $\mathrm{NaOCl}(0.4 \%)$ for 2 min and AEW for $30 \mathrm{~min}$ increased germination from $19 \%$ (control) to 41 and $54 \%$, respectively, by 7 days after treatment. Because teliospores can be treated with AEW for up to $2 \mathrm{~h}$ with little, if any, loss of viability, compared with 1 to 2 min for $\mathrm{NaOCl}$, treatment with AEW has certain advantages over $\mathrm{NaOCl}$ for surface sterilizing and increasing germination of teliospores of suspect $T$. indica.
\end{abstract}

Additional keywords: disinfestant, superoxidized water, surface sterilization

Karnal bunt of wheat, caused by Tilletia indica Mitra, is a smut disease first discovered in India in 1930 (15) and since reported to be present in Pakistan, Nepal, Iraq, Afghanistan (2), northwest Mexico (5), and recently the United States $(24,27)$. Although Karnal bunt usually causes only minor grain or seed quality reductions $(1,4)$, it is the subject of strict international quarantines (2). The presence of even a single teliospore of $T$. indica detected in a wheat shipment can cause rejection by certain countries. Following the discovery of Karnal bunt in Arizona in March 1996 $(24,27)$ and in California in April of that

Corresponding author: M. R. Bonde E-mail: bondem@ftdetrck-ccmail.army.mil

Mention of a trademark or a proprietary product does not constitute a guarantee or warranty by the U.S. Department of Agriculture and does not imply its approval to the exclusion of other products that may also be suitable.

Accepted for publication 5 April 1999.

Publication no. D-1999-0503-04R

This article is in the public domain and not copyrightable. It may be freely reprinted with customary crediting of the source. The American Phytopathological Society, 1999. year (2), field surveys for the disease were conducted in Arizona and California (2; Robert Nave, U.S. Animal and Plant Health Inspection Service, Phoenix, AZ, personal communication). Preharvest and postharvest grain samples were extracted by a technique known as "size-selective sieving" (17), and the extracted debris was examined microscopically for the presence of $T$. indica teliospores (2).

Later that year, the National Karnal Bunt Survey was initiated to determine the extent to which Karnal bunt might be present in wheat producing areas in the United States. In some instances, identification of teliospores as $T$. indica required confirmation based on a method other than microscopy because of the potential presence of teliospores of other species that were morphologically similar to those of $T$. indica (2). The method used for confirmation was based upon the polymerase chain reaction (PCR) using $T$. indica-specific DNA primers $(6,20)$ and required germination of suspect teliospores to obtain sufficient DNA for the test to be reliable. As part of the protocol to germinate $T$. indica teliospores following size-selective sieving, the extracted debris from grain samples was treated approximately 2 min with an aqueous $0.4 \%$ solution of sodium hypochlorite
$(\mathrm{NaOCl})$. These parameters had been selected to meet the combined specific requirements for the surface sterilization of teliospores and separation from debris (17). Decreasing the $\mathrm{NaOCl}$ concentration below $0.4 \%$ increased the risk of unwanted organisms growing on culture media, and the 2-min centrifugation time was selected because it was the minimum feasible for the volume being centrifuged and manipulation of multiple samples.

The $\mathrm{NaOCl}$ treatment fulfilled two important requirements: (i) it eliminated most contaminating microorganisms whose DNA could potentially interfere with the PCR assays, and (ii) it stimulated teliospore germination. A major drawback was that smut teliospores sometimes did not germinate, possibly because they were damaged by the harsh $\mathrm{NaOCl}$ treatment, or because they were dormant. The lack of teliospore germination became a major deterrent to timely identifications.

At the time the national Karnal bunt survey was being conducted, our laboratory was testing, among other things, "acidic electrolyzed water" (AEW) (16) as a possible means to decontaminate harvested grain. AEW is a product of electrolysis of a dilute solution of sodium chloride, and it contains (among other things) hypochlorous acid, a very effective sanitizer at low $\mathrm{pH}$ (25). Results of our preliminary tests indicated that AEW, at short to moderate time durations, destroyed other fungi (such as species of Aspergillus, Cladosporium, and Penicillium) while stimulating $T$. indica teliospore germination. These attributes suggested to us that AEW might be a suitable replacement for the $\mathrm{NaOCl}$ treatment in Karnal bunt disease surveys. We report here results of comparisons between AEW and $0.4 \%$ $\mathrm{NaOCl}$ to promote germination of $T$. indica teliospores and eliminate other microorganisms. All studies were conducted in the USDA plant disease containment facility at Fort Detrick, Frederick, Maryland (14), with appropriate state and federal permits.

\section{MATERIALS AND METHODS}

Source of teliospores and extraction from seeds. Teliospores used in the study were extracted from (i) Karnal bunt infected wheat seeds collected in 1995 or 1996 in Sonora, Mexico; (ii) grain harvested and stored in 1995 in Blythe, Cali- 
fornia, or (iii) commercial grain being sold in a marketplace in 1997 in Hoshur, India.

Teliospores were collected from infected seeds by placing individual bunted kernels into four drops of $0.1 \%$ Tween 20 (sodium monolaurate) in small plastic weighing boats. After wetting a kernel, we scraped spores from the sorus using a dissecting needle. Loose spores and the kernel were poured onto a 53- $\mu \mathrm{m}$ pore size nylon mesh screen and rinsed thoroughly with sterile distilled water. The material that passed through the 53- $\mu \mathrm{m}$ screen was then poured onto a $20-\mu \mathrm{m}$ pore size nylon mesh screen. Teliospores that collected on the screen were washed into a $15-\mathrm{ml}$ centrifuge tube, pelleted by centrifugation at $200 \times g$, and resuspended in distilled water as a stock teliospore suspension. The teliospore concentration was determined by hemacytometer count, and an aliquot providing approximately 1,500 spores for each $5-\mathrm{cm}$ diameter petri plate of an experiment was centrifuged to produce a pellet. The spore pellet was used immediately.

Preparation of AEW. AEW was generated by electrolysis in a Super Oxseed Laboratory JED 020 apparatus (Advanced $\mathrm{H}_{2} \mathrm{O}$, Alameda, CA), in which an electric current was passed through a dilute aqueous solution of sodium chloride. Acidic electrolyzed water (AEW) was generated in the anode compartment and alkaline water in the cathode compartment. AEW was prepared fresh each day of an experiment according to the manufacturer's directions. Sodium chloride $(0.70 \mathrm{~g})$ was dissolved in 4 liters of tap water, 2 liters each was poured into the anode and cathode compartments, and electrolysis was allowed to proceed for $15 \mathrm{~min}$. The $\mathrm{pH}$, oxidation/reduction potential (ORP), and free chlorine content were determined at the beginning and end of the treatment phase of each experiment by means of a $\mathrm{pH}$ meter, redox meter, and spectrophotometric analysis at $528 \mathrm{~nm}$ using $N, N$-diethyl- $p$-phenylenediamine $(21,25)$, respectively.

Table 1. Numbers of fungal colonies growing as containments (other than Tilletia indica) on $2 \%$ AW agar $^{\mathrm{a}}$ at 9 or 14 days following seeding plates with extracted debris from wheat samples ${ }^{\mathrm{b}}$

\begin{tabular}{lccc}
\hline & & \multicolumn{2}{c}{$\begin{array}{c}\text { Mean no. fungal colonies } \\
\text { per 50-g wheat sample }\end{array}$} \\
\cline { 3 - 4 } Wheat cultivar/type & Days after plating & 2 min $\mathbf{0 . 4 \%}$ NaOC1 & 20 min AEW \\
\hline Yocora Rojo (durum) & 14 & 0 & 13.4 \\
No. 1 hard red spring & 14 & 0 & 0.3 \\
No. 2 hard red spring & 9 & 1.3 & 0.3 \\
Madsen (durum) & 9 & 0 & 0.7 \\
Renville (durum) & 9 & 0 & 1.3 \\
Average for treatment & & 0.3 & 3.2 \\
\hline
\end{tabular}

a Water agar amended with $100 \mathrm{mg}$ each of streptomycin sulfate and ampicillin per liter to prevent bacterial growth.

b Debris was extracted from three 50-g samples per wheat cultivar and soaked overnight in sterile distilled water prior to $\mathrm{NaOC} 1$ or acidic electrolyzed water (AEW) treatment. Treated debris from each wheat wash was plated onto AW agar in one $10-\mathrm{cm}$-diameter petri plate. Means are average of three replicates. Wheat debris receiving no treatment (control) had too much contamination to quantitate.

${ }^{\mathrm{c}}$ Grain elevator wheat sample from Blythe, California, containing some natural $T$. indica infection.

d Grain Inspection, Packers, and Stockyards Administration (GIPSA) sample collected at a U.S. export elevator at the Gulf of Mexico and containing no T. indica teliospores.
To terminate the treatments in each experiment, the liquid was removed by vacuum filtration, and the teliospores were immediately rinsed with $10 \mathrm{ml}$ of sterile $0.1 \%$ aqueous Tween 20 solution, followed by two washes $(10 \mathrm{ml}$ each $)$ of sterile distilled water. The filters were aseptically removed from the funnels and placed inverted onto the surface of $2 \%$ water agar containing $100 \mathrm{mg}$ each of streptomycin sulfate and ampicillin per liter (AW agar) in 5-cm-diameter plastic petri plates. After gently pressing the filters to the AW agar surface and rubbing with a pair of forceps to ensure good contact and transfer of spores to the agar surface, the filters were removed and discarded. Lids were replaced, and the plates were incubated at $20^{\circ} \mathrm{C}$, with a 12 -h light period.

In some tests, a 1-min $\mathrm{NaOCl}$ and a 1-min AEW treatment were added. For 1-min treatments, a spore suspension was placed directly onto the Millipore filter in the funnel and covered with $\sim 10 \mathrm{ml}$ of $0.4 \% \mathrm{NaOCl}$ solution or AEW to initiate the treatment. After $1 \mathrm{~min}$, to terminate the treatment, the liquid was immediately removed by suction and spores were rinsed with $0.1 \%$ Tween 20 followed by two washes with sterile distilled water. The teliospores were transferred to the surface of AW agar, and plates were incubated as previously described. All plates were examined for germination at 3, 4, 5, 7, and 14 days after plating, unless otherwise indicated.

Effect of $\mathrm{NaOCl}$ at different concentrations on teliospore germination. The experiment was conducted twice, once with nonreplicated treatments (three replicate samples per treatment flask) and once with three replicates per treatment. In the latter, aqueous $\mathrm{NaOCl}$ solutions of $0.2,0.3$, and $0.4 \%$ were prepared by dilution of $5.25 \%$ commercial bleach with distilled water. Teliospores were placed in the $\mathrm{NaOCl}$ solutions in three $125-\mathrm{ml}$ Erlenmeyer flasks per $\mathrm{NaOCl}$ concentration and suspended by means of magnetic stir bars. After 2, 5, 10, 15, and $30 \mathrm{~min}$, a 10-ml aliquot was removed from each flask and immediately filtered. The teliospores on the filters were rinsed, transferred to AW agar, incubated at $20^{\circ} \mathrm{C}$, and examined for germination at 7 and 14 days as previously described.

Determination of germination percentages. Teliospores were examined microscopically at $\times 100$ magnification to determine germination percentages. Teliospores were considered germinated when basidiospores (primary sporidia) had formed. Two hundred nonbroken mature teliospores were examined for each of three replicates.

Determination of effects of AEW or $\mathrm{NaOCl}$ on teliospore appearance. Teliospores that had been incubated in AEW or $0.4 \% \mathrm{NaOCl}$ for specific durations from 0 to $30 \mathrm{~min}$ were examined microscopically at $\times 100$ and $\times 400$ magnification to deter- 
mine if physical changes had occurred and photographed for documentation.

Comparison of $\mathrm{AEW}$ and $\mathrm{NaOCl}$ for controlling contamination in wheat washes. Nine 50-g wheat samples per each of two wheat lots (Table 1) were extracted according to the size-selective sieving technique (17). Approximately 10,000 teliospores from a teliospore collection from Sonora, Mexico, or a collection from Blythe, California, were added to each wheat wash. The seeded washes were incubated overnight at $20^{\circ} \mathrm{C}$. The following day, the wheat wash of each of three samples (equal replicates) for each of the two wheat lots was treated for $20 \mathrm{~min}$ with $\mathrm{AEW}$, and three were treated for $2 \mathrm{~min}$ with $0.4 \% \mathrm{NaOCl}$ (actual time 2 min $16 \mathrm{~s}$ ). Three wheat washes of each wheat type received no $\mathrm{AEW}$ or $\mathrm{NaOCl}$ treatment and
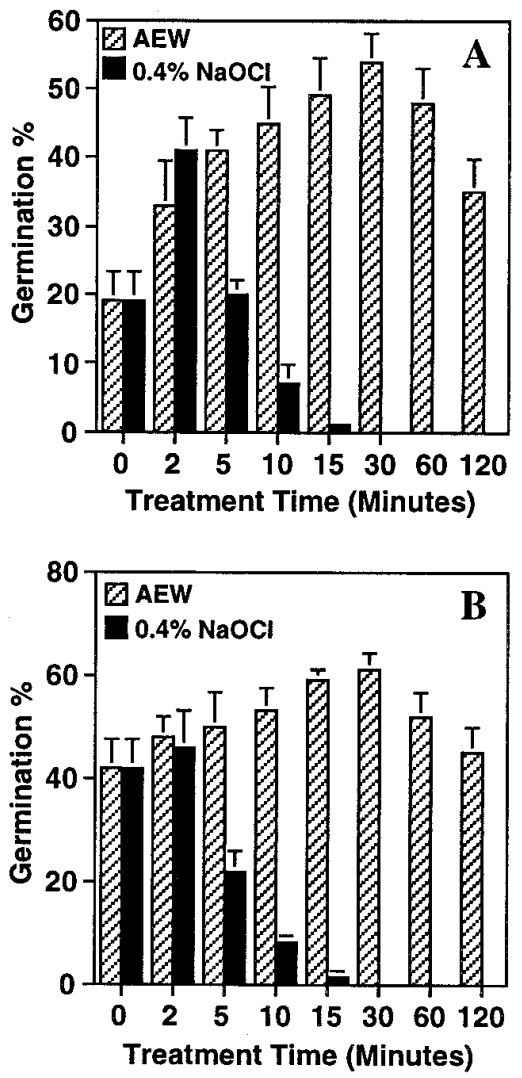

Fig. 1. Effects of 2- to 30-min treatments with $0.4 \% \mathrm{NaOCl}$ and 2- to 120 -min treatments with acidic electrolyzed water (AEW), respectively, on Tilletia indica teliospore germination as observed at (A) 7 days, and (B) 14 days after plating treated teliospores onto water agar containing $100 \mathrm{mg}$ each of streptomycin sulfate and ampicillin per liter (AW agar). Germination percentages are based on 200 spores for each of three replicates per $\mathrm{NaOCl}$ or $\mathrm{AEW}$ treatment time. The 0-min treatment (three replicates) serves as control for both the $\mathrm{NaOCl}$ and AEW treatments. Bars represent one standard deviation. Note the marked increase in germination with either 2-min AEW or 2-min $0.4 \% \mathrm{NaOCl}$ treatment compared with the control $(0 \mathrm{~min})$ treatment, when observed 7 days after plating. served as controls. Following the treatments, the samples were centrifuged for 1 $\min$ at $200 \times g$, and the pellets were washed twice with sterile distilled water, resuspended, and plated onto AW agar. All plates were incubated at $20^{\circ} \mathrm{C}, 12$-h day, and examined at $\times 100$ magnification at 3 , $4,5,7$, and 14 days after seeding plates to determine $T$. indica germination percentages and contamination levels.

Three additional wheat lots (Table 1) without teliospores also were extracted and treated as above. After treatment for 20 min with AEW or 2 min with $0.4 \%$ $\mathrm{NaOCl}$, the debris from these samples was plated onto AW agar. The plates were incubated as previously described and examined at 9 and 14 days to determine contamination levels.

\section{RESULTS}

Effects of $0.4 \% \mathrm{NaOCl}$ and AEW on teliospore germination. The effectiveness of treatments with $\mathrm{AEW}$ and $0.4 \% \mathrm{NaOCl}$ on $T$. indica teliospore germination was compared in six experiments. Except for the 1-min treatments, where results were inconsistent (data not presented), results among experiments were nearly identical, and each gave the same conclusions. During the treatment phase of each experiment, the pH (2.5 to 2.6) and ORP $(1,100$ to $1,200 \mathrm{mV}$ ) of AEW did not significantly change. The free chlorine content (initially 11.0 to $16.0 \mathrm{ppm}$ ) decreased by approximately $25 \%$ in $30 \mathrm{~min}$ and $80 \%$ in 120 min. The $\mathrm{pH}$ (approximately 9.2) and free chlorine content $(2,600$ to $3,600 \mathrm{ppm})$ of the $0.4 \% \mathrm{NaOCl}$ solution remained constant.

Germination percentages of teliospores placed in distilled water and stirred for durations up to $120 \mathrm{~min}$ did not differ significantly ( $t$ test) from those of teliospores

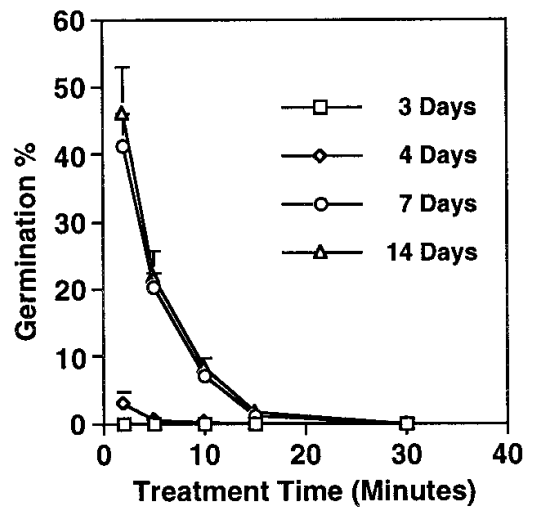

Fig. 2. Effects of 2- to 30-min treatments with $0.4 \% \mathrm{NaOCl}$ on Tilletia indica teliospore germination as observed at $3,4,7$, and 14 days after plating treated teliospores on water agar containing $100 \mathrm{mg}$ each of streptomycin sulfate and ampicillin per liter (AW agar). Germination was first observed at 4 days. Percentages are based on 200 teliospores for each of three replicates per $\mathrm{NaOCl}$ or AEW treatment time. Bars represent one standard deviation. placed immediately on AW agar (data not presented).

Germination percentages at 7 and 14 days after plating teliospores treated for 2 to $30 \mathrm{~min}$ with $0.4 \% \mathrm{NaOCl}$ or 2 to 120 min with AEW are presented in Figure 1. At 7 days (Fig. 1A), whereas only 19\% of control (nontreated) teliospores had germinated, 41 and $33 \%$ of the 2-min NaOCland AEW-treated teliospores, respectively, had germinated. The germination of teliospores 7 days after a 5-min exposure to $\mathrm{NaOCl}$ was $20 \%$ and significantly ( $t$ test, $P$ $<0.0001)$ less than that of those exposed for $5 \mathrm{~min}$ to $\mathrm{AEW}$, which had germinated at $41 \%$. Germination of NaOCl-treated teliospores decreased to $7 \%$ by $10 \mathrm{~min}$ and $0.0 \%$ by $30 \mathrm{~min}$. In contrast, AEW-treated spores germinated optimally over the range of 10 to $60 \mathrm{~min}$, with germination percentages ranging from 45 to $54 \%$.

At 14 days (Fig. 1B), $0.4 \%$ NaOCltreated teliospores had germinated optimally $(46 \%)$ with the 2-min treatment, and decreased to $8 \%$ by $10 \mathrm{~min}$ and $0.0 \%$ by 30 min. In every experiment except one, no $T$. indica teliospores survived $0.4 \% \mathrm{NaOCl}$ longer than $15 \mathrm{~min}$. In that exception, $0.1 \%$ survived the 30-min treatment. At 14 days after treatment with AEW, teliospores had germinated optimally with treatment times of 15 to $30 \mathrm{~min}$ (59 to $61 \%$ germination). The germination of teliospores with even the 120-min exposure to AEW was not significantly ( $t$ test, $P<0.0001$ ) less than that of those exposed for 2 min to AEW.

Germination percentages at 3, 4, 7, and 14 days for the $0.4 \% \mathrm{NaOCl}$ and AEW treatments, respectively, are presented in Figures 2 and 3. No germination was observed at 3 days with any treatment. By 4 days, a maximum of $4 \%$ had germinated, and by 7 days, nearly as many teliospores were germinated as at 14 days.

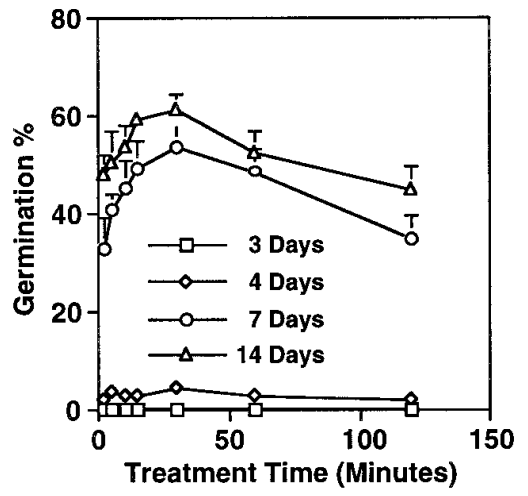

Fig. 3. Effects of 2- to 120-min treatments with acidic electrolyzed water (AEW) on Tilletia indica teliospore germination as observed at 3 , 4,7 , and 14 days after plating treated teliospores on water agar containing $100 \mathrm{mg}$ each of streptomycin sulfate and ampicillin per liter (AW agar). Percentages are based on 200 teliospores for each of three replicates per $\mathrm{NaOCl}$ or AEW treatment time. Bars represent one standard deviation. 
Effects of $\mathrm{NaOCl}$ concentration on teliospore germination. Germination percentages for $T$. indica teliospores 14 days after treatment with $0.2,0.3$, and $0.4 \%$ $\mathrm{NaOCl}$ are presented in Figure 4. At each concentration, the highest germination percentage was with the 2-min treatment. Whereas $38 \%$ of nontreated (control) teliospores germinated by 14 days, treated spores germinated at 66,57 , and $52 \%$ with the 2-min $0.2,0.3$, and $0.4 \% \mathrm{NaOCl}$ treatments, respectively. No teliospores survived for $30 \mathrm{~min}$, regardless of $\mathrm{NaOCl}$ concentration.

Effects of $\mathrm{NaOCl}$ and $\mathrm{AEW}$ on contaminants. No bacterial colonies were observed with any of the NaOCl-treated and AEW-treated samples, respectively (Table 1). Fungal colonies grew from only one NaOCl-treated sample (treatment average of 0.3 colonies per wheat wash), and from a few samples (treatment average of 3.2 colonies per wheat wash) for AEWtreated wheat (Table 1). Of the AEWtreated samples, four of the five averaged 1.3 or fewer contaminating fungal colonies. Contamination following either the $\mathrm{NaOCl}$ or AEW treatment was never extensive enough to interfere with determination of germination percentages for $T$. indica. In contrast, extensive contamination in control (nontreated) plates prevented determination of colony numbers and germination percentages.

Effects of $\mathrm{NaOCl}$ and AEW on teliospore appearance. Microscopic examination of teliospores subjected to $0.4 \%$ $\mathrm{NaOCl}$ revealed changes by $2 \mathrm{~min}$ (Fig. $5 \mathrm{~A}$ versus 5B). At 2 min (Fig. 5B), teliospores had become lighter in color, the apparent result of bleaching of spore wall pigments, and spore walls were thicker. With progressively longer $\mathrm{NaOCl}$ treatments, pig-

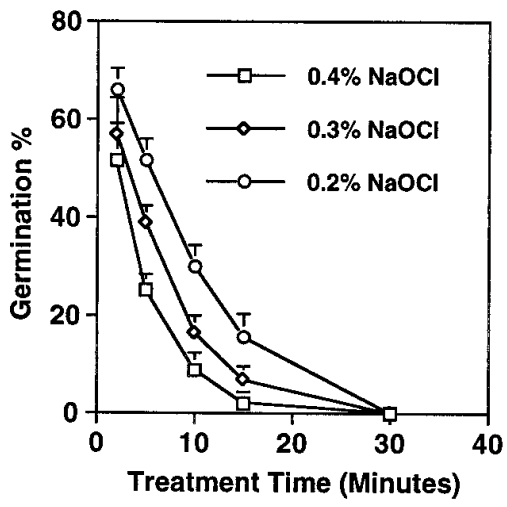

Fig. 4. Effects of 2- to 30-min treatments with $0.4,0.3$, and $0.2 \% \mathrm{NaOCl}$ on Tilletia indica teliospore germination as observed at 14 days after plating treated teliospores on water agar containing $100 \mathrm{mg}$ each of streptomycin sulfate and ampicillin per liter (AW agar). Teliospores receiving 0 -min treatment germinated at $38 \%$ (data not shown). Percentages are based on 200 teliospores for each of three replicates per $\mathrm{NaOCl}$ or AEW treatment time. Bars represent one standard deviation. mentation loss and spore wall thickening were more pronounced (Fig. 5C). By 15 min with AEW, no obvious changes were apparent (Fig. 5D).

\section{DISCUSSION}

The inability to germinate teliospores often has been a detriment to timely identification. PCR-based diagnostic tests have been extremely helpful in confirming the identity of $T$. indica teliospores. However, in order to obtain sufficient DNA for these tests, suspect teliospores had to be germinated. Treatment of $T$. indica teliospores with either $\mathrm{NaOCl}$ or AEW can increase teliospore germination. Although either treatment can control contamination on germination media, our study has shown that teliospore treatment with AEW has several advantages. Foremost is a much broader window for treatment duration without danger of killing smut teliospores. Other advantages include an increase in personnel and environmental safety. AEW reverts to normal water following use without release of large amounts of harmful gases, such as chlorine. Finally, after the initial cost of the electrophoresis apparatus, operational expenses are minimal.

The standard protocol following extracting teliospores from wheat samples has been to soak the extracted debris overnight in water. The debris then was treated for 2 min with a $0.4 \%$ aqueous solution of $\mathrm{NaOCl}(8 \%$ commercial bleach) and plated onto AW agar. During the overnight soaking period, presumably most fungal spores, other than those of smut pathogens, imbibed sufficient water to initiate germination. Germinating fungal spores are very susceptible to even brief exposures to $\mathrm{NaOCl}$ (M. R. Bonde, S. E. Nester, and J. L. Smilanick, personal observations). Teliospores of smut pathogens are more resistant to $\mathrm{NaOCl}$ and $\mathrm{AEW}$ than are spores of most fungi, perhaps because they require a longer time to initiate germination. Whereas spores of many fungi can germinate in a few hours, smut teliospores can take 1 to 8 weeks (3).

A possible explanation for the inability of teliospores to germinate following treatment with $\mathrm{NaOCl}$ in the national Karnal bunt survey is that the harsh $\mathrm{NaOCl}$ treatment killed them. An alternative explanation is that the teliospores were dormant. Our study showed that while a 1- to 2-min $\mathrm{NaOCl}$ treatment increased germination, exposure to $0.4 \% \mathrm{NaOCl}$ for periods longer than $2 \mathrm{~min}$ greatly reduced germination, and few survived past $10 \mathrm{~min}$. When the $\mathrm{NaOCl}$ concentration was decreased to 0.3 and $0.2 \%$, teliospore germination increased (Fig. 4). However, increases in treatment time beyond $2 \mathrm{~min}$ still progressively lowered germination,

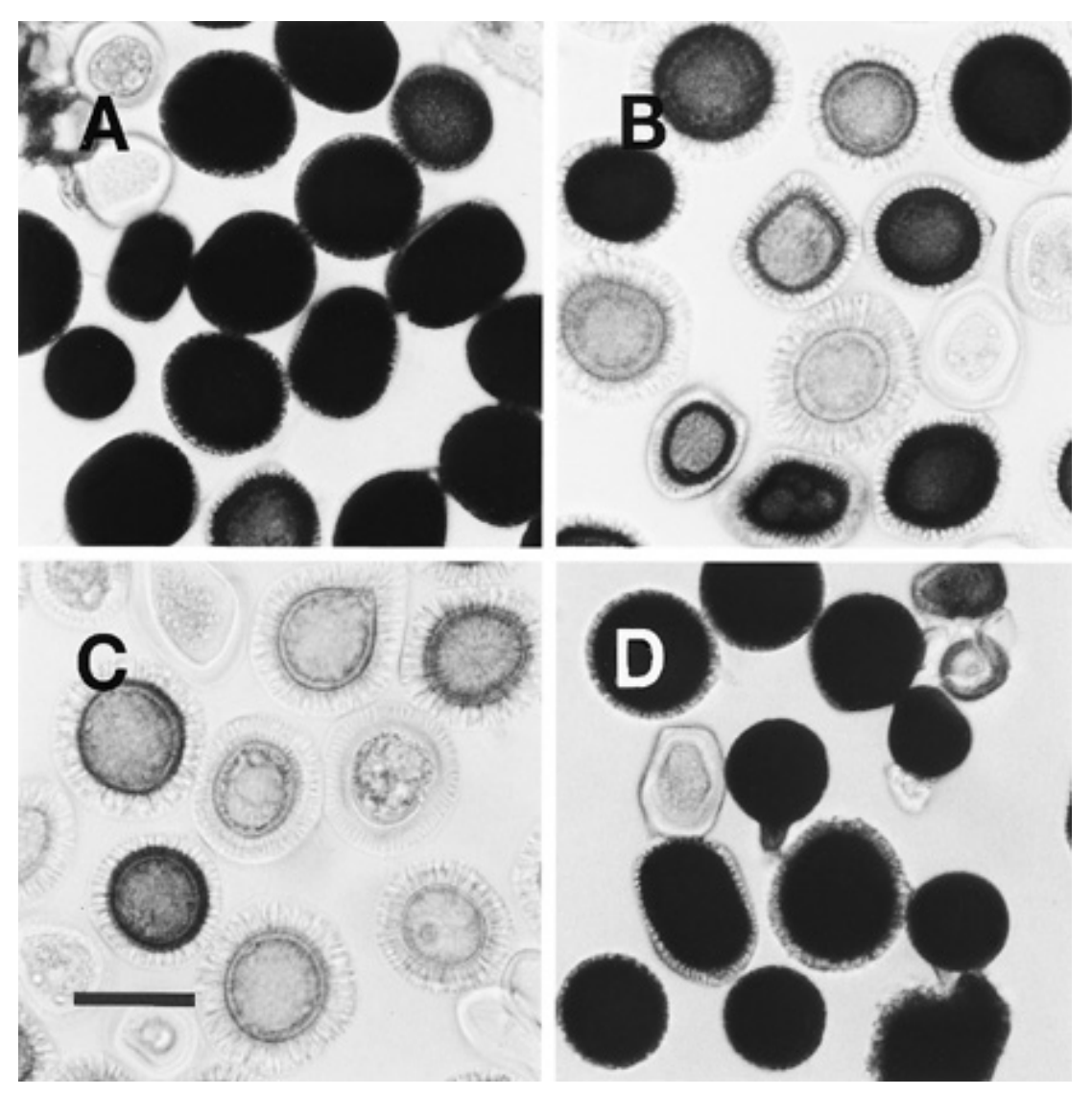

Fig. 5. Tilletia indica teliospores treated with $0.4 \% \mathrm{NaOCl}$ for (A) $0 \mathrm{~min}$, (B) $2 \mathrm{~min}$, and (C) $5 \mathrm{~min}$, and (D) with acidic electrolyzed water (AEW) for $15 \mathrm{~min}$. Note that even with a 2-min $\mathrm{NaOCl}$ treatment, teliospores are much lighter in color, and teliospore walls are considerably thickened. At 15 min with AEW, teliospores remain essentially the same as control in appearance. 
and by $15 \mathrm{~min}$, few teliospores germinated (Fig. 4).

AEW is produced by the electrolysis of a dilute solution of sodium chloride $(\mathrm{NaCl})$. Chlorine $\left(\mathrm{Cl}_{2}\right)$ is generated in the anode chamber, and hydrogen $\left(\mathrm{H}_{2}\right)$ in the cathode chamber. The chlorine reacts with the water (in the anode chamber) to form hypochlorous acid and hydrochloric acid according to the following reaction:

$$
\mathrm{Cl}_{2}+\mathrm{H}_{2} \mathrm{O} \leftrightarrow \mathrm{HOCl}+\mathrm{HCl}
$$

At the low $\mathrm{pH}$ of AEW, the hypochlorous acid, which is a very weak acid and also a very effective sanitizer, undergoes virtually no hydrolysis to the much less effective hypochlorite ion $\left(\mathrm{OCl}^{-}\right)(10,25)$. Hypochlorite ion, on the other hand, is the main species present in commercial hypochlorite solutions. Molecular chlorine, probably in equilibrium with the hypochlorous acid (25), and known to be present in AEW, also is an extremely effective sanitizer (25). Hypochlorous acid and free chlorine are probably major contributors to AEWs sanitizing effectiveness.

Because the free chlorine content in AEW dropped significantly (by $80 \%$ ) during the $120 \mathrm{~min}$ of stirring in our study while the ORP remained constant, other strong oxidants undoubtedly are present. According to Khayat (unpublished data), a cascade of redox reactions occurs during electrolysis that produces many reactive and toxic compounds, such as ozone, and very highly reactive and short-lived radicals such as $\mathrm{O} \cdot, \mathrm{Cl} \cdot$, and $\mathrm{OH} \cdot$ in the anode chamber (18), and these contribute to the sanitizing effect of AEW. However, the exact nature of the sanitation effect of AEW has yet to be elucidated.

In our study, we manufactured AEW by electrolysis of tap water containing a small amount of sodium chloride, using the exact protocol prescribed by the manufacturer of the electrolysis unit. Further studies (data not included) showed AEW manufactured from distilled water had nearly identical $\mathrm{pH}$, ORP, and free chlorine concentration as that produced from tap water, and effects on $T$. indica teliospore germination were not significantly different.

AEW also has been referred to as electrolyzed strong acid aqueous solution (ESAAS) $(8,12)$, electrolyzed water, acidic electrolyzed water (16), strong ionized water (18), electrolyzed saline solution (26), functional water (11), and superoxidized water (12). Most research on the sanitizing effects of AEW has been conducted with bacteria, and results show a variety of gram-positive and gram-negative bacteria are killed within $10 \mathrm{~s}$ (23). In medical practice in Japan, AEW is used to treat mediastinitis infection after cardiovascular surgery, in addition to other infections such as peritonitis (23). With patients developing mediastinitis following heart surgery, AEW was flushed into the chest cavity over a period of several days, with remarkable results at clearing the infection (8). Several Japanese hospitals routinely use AEW, which is piped to various sites within the hospital from its production point, for surface sterilizing and hand washing (16). Although studies in Japan show AEW very effective against bacteria, we cannot conclude this from our data since we routinely incorporated antibiotics into our germination medium. However, our data do show AEW to be effective against most fungi in wheat samples.

We demonstrated that treating $T$. indica teliospores, by themselves or in wheat extracts, for 15 to 20 min with AEW resulted in higher germination than the standard 2-min treatment with $0.4 \% \mathrm{NaOCl}$. Since stirring $T$. indica teliospores in water for durations up to $120 \mathrm{~min}$ had no or little effect on germination, the increase in germination we observed with AEW (or $\mathrm{NaOCl}$ solution) was not due solely to contact of teliospores with water. In only one sample in which wheat was extracted by means of the technique of size-selective sieving and extracted debris treated with $0.4 \% \mathrm{NaOCl}$ and AEW, respectively, was contamination with the AEW treatment considerably higher than with $\mathrm{NaOCl}$. That sample had been intentionally selected because it was extremely dirty and suspected of having a high level of contamination commonly associated with poor grain quality. However, even in that instance, contamination was controlled and did not prevent examination of $T$. indica teliospores and determination of germination percentages. We also are using AEW to surface-sterilize $T$. indica teliospores extracted from field soil and find nearly total prevention of growth of organisms other than T. indica (M. R. Bonde and S. E. Nester, unpublished data).

Teliospores of $T$. indica, as with other smut pathogens, are very resistant to chemical treatments $(9,22)$. The resistance of $T$. indica teliospores to AEW and $\mathrm{NaOCl}$, as evidenced in this study, allowed elimination of nearly all microorganisms other than $T$. indica, thus providing pure cultures for identification by PCR and shortening the average time required for germination. The acceptable duration for treating teliospores with $\mathrm{AEW}$ is very broad, from as little as $5 \mathrm{~min}$ to as long as at least $60 \mathrm{~min}$. This is in marked contrast to $0.4 \% \mathrm{NaOCl}$, where samples can be in contact with the solution for only $2 \mathrm{~min}$ without a major decrease in germination, leaving little margin for error and precluding testing large numbers of samples simultaneously. A decrease in $\mathrm{NaOCl}$ concentration to 0.3 and $0.2 \%$ results in higher germination but does not extend the time before germination is greatly reduced (Fig. 4). Furthermore, decreasing the concentration increases the likelihood for growth of other organisms.

In our study, $\mathrm{NaOCl}$ and $\mathrm{AEW}$, compared with no treatment, each increased the numbers of teliospores that germinated by 14 days on AW agar. It is possible that the nontreated (control) teliospores would have had as high a germination as $\mathrm{NaOCl}$ - or AEW-treated teliospores if they could have been held past 14 days. However, at times longer than 14 days, contamination usually covered the control plates, making teliospore examinations impossible.

Boyd and Carris (3) increased germination of teliospores of Tilletia controversa, T. tritici, T. bromi, and T. fusca by adding $1.0 \%$ activated charcoal to the germination medium (water agar), presumably removing endogenous spore germination inhibitors from the teliospores. In two experiments ancillary to our study, we added $1.0 \%$ activated charcoal to water agar, but we observed no increase in teliospore germination of $T$. indica. In fact, there tended to be a decrease in germination, perhaps due to removal of one or more factors, such as nutrients, that promote germination.

The mechanism by which AEW affects living organisms is not known. The extremely high oxidation/reduction potential of AEW obviously is a factor in sterilization. In a study ancillary to this study, in which we compared AEW (pH 2.5) with $\mathrm{pH} 2.5$ buffered water (7), we observed no significant differences ( $t$ test) in germination percentages. This suggested that $\mathrm{pH}$ by itself was not a factor in AEW stimulation of $T$. indica teliospore germination.

When teliospores of $T$. indica are first produced, they are dormant for 2 to 9 months (13). If tested for viability in this state, they have a germination percentage of only 1 to $2 \%$ (19). Singh (19) showed that one or more water soluble compounds (inhibitors) are responsible for young teliospores' inability to germinate. We observed that winter temperatures in Maryland could induce dormancy in $T$. indica teliospores buried in the field (under appropriate state and federal permits) (M. R. Bonde and G. L. Peterson, unpublished data). The dormancy lasted approximately 3 months. However, we do not know the nature of this cold induced dormancy nor its relationship to the dormancy inherent in young teliospores. It will be interesting to learn if $\mathrm{NaOCl}$ and/or AEW can break teliospore dormancy. Teliospore dormancy is a key factor in disease initiation, establishment, and pathogen persistence, and is being actively studied in our laboratory.

\section{ACKNOWLEDGMENTS}

We sincerely thank Edward Alexander, Advanced $\mathrm{H}_{2} \mathrm{O}$, for providing the electrolysis apparatus and for helpful guidance in its use; Gerhard F. Knapp, GFK Consulting Ltd., for information pertaining to the chemistry of chlorination; Roy Gingery, Robert Nave, and Stephen Poe for helpful suggestions during the study; and Gail Hoover for typing the manuscript.

\section{LITERATURE CITED}

1. American Phytopathological Society. 1996. Position statement. The American Phytopa- 
thological Society: The use of quarantines for wheat Karnal bunt. APS net. Published online: Karnal Bunt Symposium.

2. Bonde, M. R., Peterson, G. L., Schaad, N. W., and Smilanick, J. L. 1997. Karnal bunt of wheat. Plant Dis. 81:1370-1377.

3. Boyd, M. L., and Carris, L. M. 1998. Enhancement of teliospore germination in wheat- and wild grass-infecting species of Tilletia on activated charcoal medium. Phytopathology 88:260-264.

4. Butler, L. 1990. Karnal bunt, quarantine and the international shipment of CIMMYT wheat seed. Proc. Bienn. Workshop Smut Fungi, 7th, Frederick, MD.

5. Duran, R. 1972. Further aspects of teliospore germination in North American smut fungi. Can. J. Bot. 50:2569-2573.

6. Ferreira, M. A. S. V., Tooley, P. W., Hatziloukas, E., Castro, C., and Schaad, N. W. 1996. Isolation of a species-specific mitochondrial DNA sequence for identification of Tillitia indica, the Karnal bunt of wheat fungus. Appl. Environ. Microbiol. 62:87-93.

7. Gomori, G. 1955. Preparation of buffers for use in enzyme studies. Pages 138-146 in: Methods in Enzymology. S. P. Colowick and N. O. Kaplan, eds. Academic Press, Inc., New York.

8. Hayashi, H., Kumon, K., Yahagi, N., Haruna, M., Watanabe, Y., Matsui, J., and Hattori, R. 1997. Successful treatment of mediastinitis after cardiovascular surgery using electrolyzed strong acid aqueous solution. Artif. Organs 21:39-42.

9. Hoffman, J. A. 1986. Chemical seed treatments for Karnal bunt. Proc. Bienn. Smut Worker's Workshop, 5rd. Ciudad Obregon, Mexico.
10. Kohno, M. 1996. ESR detection of active oxygen. Joel Ltd. Page 52 in: Functional Water Symposium, Japan.

11. Kumon, K. 1997. What is functional water? Artif. Organs 21:2-4.

12. Kumon, K., Yahagi, N., Imanaka, H., and Takeuchi, M. Medical utilities of electrolyzed strong acid aqueous solutions in a surgical intensive care unit for the prevention of nosocomial infection. Proc. Functional Water Symp., 1997, Japan. In press.

13. Mathur, S. B., and Cunfer, B. M. 1993. Karnal bunt. Pages 31-43 in: Seed-borne Diseases and Seed Health Testing of Wheat. Jordbrugsforlaget Frederiksberg, Denmark.

14. Melching, J. S., Bromfield, K. R., and Kingsolver, C. H. 1983. The plant pathogen containment facility at Frederick, Maryland. Plant Dis. 67:717-722.

15. Mitra, M. 1931. A new bunt of wheat in India. Ann. Appl. Biol. 18:178-179.

16. Nakamura, Y., and Iwasawa, A. The effects of the acidic electrolyzed water on the prevention of hospital-acquired infection. Proc. Functional Water Symp., 1997, Japan. In press.

17. Peterson, G. L., Bonde, M. R., Schaad, N. W., and Phillips, J. G. 1998. Development and utilization of size-selective sieving for rapid detection of teliospores of Tilletia indica Mitra, the causal agent of Karnal bunt of wheat. Phytopathology 88:S131.

18. Shiba, A., and Shiba, K. 1995. Strong Ionized Water Handbook. Department of Dentistry, Showa University and Department of Dentistry, Tokyo Medical and Dental University. Igoku Joho Co. Ltd. Publisher.

19. Singh, A. 1994. Epidemiology and Manage- ment of Karnal Bunt Disease of Wheat. Directorate of Experiment Station. Res. Bull. 127. GB Pant University of Agriculture and Technology, Pantnagar, India.

20. Smith, O. P., Peterson, G. L., Beck, R. J., Schaad, N. W., and Bonde, M. R. 1996. Development of a PCR-based method for identification of Tillitia indica, causal agent of Karnal bunt of wheat. Phytopathology $86: 115-122$.

21. Smilanick, J. L., Hershberger, W., Bonde, M. R., and Nester, S. E. 1997. Germinability of teliospores of Tillitia indica after hot water and sodium hypochlorite treatments. Plant Dis. 81:932-935.

22. Smilanick, J. L., Hoffmann, J. A., Secrest, L. R., and Wiese, K. 1988. Evaluation of chemical and physical treatments to prevent germination of Tillitia indica teliospores. Plant Dis 72:46-51

23. Tanaka, H., Hirakata, Y., Kaku, M., Yoshida, R., Takemura, H., Mizukane, R., Ishida, K. Tomono, K., Koga, H., Kohno, S., and Kamihira, S. 1996. Antimicrobial activity of super oxidized water. J. Hosp. Infect. 34:43-49.

24. Washington Post. 1996. Declaration of extraordinary emergency. March 22. p. A23

25. White, G. C. 1992. Handbook of Chlorination and Alternative Disinfectants. Van Nostrand Reinhold, New York

26. Wilk, I. J., Altmann, R. S., and Berg, J. D. 1987. Antimicrobial activity of electrolyzed saline solutions. Sci. Total Environ. 63:191 197.

27. Ykema, R. E., Floyd, J. P., Palm, M. E., and Peterson, G. L. 1996. First report of Karnal bunt of wheat in the United States. Plant Dis. 80:1207. 